\title{
Experimental Investigation on Mechanical Behaviour of Kevlar and Ramie Fibre Reinforced Epoxy Composites
}

\author{
V. Vedanarayanan, ${ }^{1}$ B. S. Praveen Kumar, ${ }^{2}$ M. S. Karuna, ${ }^{3}$ A. Jayanthi, ${ }^{4}$ \\ K. V. Pradeep Kumar, ${ }^{5}$ A. Radha, ${ }^{6}$ G. Ramkumar $\mathbb{D}^{7},{ }^{7}$ and David Christopher $\mathbb{D}^{8}$ \\ ${ }^{1}$ Department of Electronics and Communication Engineering, Sathyabama Institute of Science and Technology, Chennai, \\ Tamil Nadu 600119, India \\ ${ }^{2}$ Department of Mechanical Engineering, Presidency University, Bengaluru, Karnataka 560064, India \\ ${ }^{3}$ Department of Chemical Engineering, M.J.P. Rohilkhand University, Bareilly, Uttar Pradesh 243006, India \\ ${ }^{4}$ Department of Chemistry, Panimalar Institute of Technology, Chennai, Tamilnadu 600123, India \\ ${ }^{5}$ Department of Mechanical Engineering, M S Ramaiah Institute of Technology, Bengaluru, Karnataka 560054, India \\ ${ }^{6}$ Department of Mechanical Engineering, Loyola-ICAM College of Engineering and Technology, Chennai, Tamil Nadu 600034, India \\ ${ }^{7}$ Department of Electronics and Communication Engineering, Saveetha School of Engineering, SIMATS, Chennai, \\ Tamil Nadu 602105, India \\ ${ }^{8}$ Department of Mechanical Engineering, College of Engineering, Wolaita Sodo University, Ethiopia
}

Correspondence should be addressed to David Christopher; david.santosh@wsu.edu.et

Received 28 November 2021; Accepted 5 January 2022; Published 2 February 2022

Academic Editor: Palanivel Velmurugan

Copyright (c) 2022 V. Vedanarayanan et al. This is an open access article distributed under the Creative Commons Attribution License, which permits unrestricted use, distribution, and reproduction in any medium, provided the original work is properly cited.

\begin{abstract}
Natural fibre composites have been replacing synthetic fibre composites in practical applications for the last several years because of the features such as low densities, low weight, relatively inexpensive, recyclability, and excellent mechanical qualities unique to the substance. Thus, the current study examines how Kevlar/Ramie/Nano SiC hybrid fibre reinforced composites are made and their mechanical properties, and it compares them to those made using a single natural fibre reinforced composite. It was found that natural fibre composite densities and hardness were all within acceptable ranges by performing composites' tensile and flexural strength tests. The hand-lay-up technique used ASTM standards samples to construct the composite specimens with various fibre weight percentages. Increase in mechanical characteristics was achieved by adding the glass and the epoxy fibres into the epoxy matrix. The hybrid composite's performance is promising, especially those of individual fibre-reinforced composites.
\end{abstract}

\section{Introduction}

Polymer composites are found in a wide range of products that we use every day. There are numerous applications for composites in the automotive and marine industries. Excellent resistance to corrosion as well as high ratios of stiffness to weight all play a role in these applications' resilience and creep resistance [1]. Scientific and scientific interests in the use of natural fibres in consumer goods and civic buildings have been piqued as a result of the prohibitive price of synthetic fibres for use in aircraft and military applications, including, but not limited to banana, coconut husks, hemp, and sisal. Biodegradable, renewable, nontoxic, combustibil- ity, and high specific mechanical characteristics are just a few of the advantages that natural fibres offer over traditional fibres [2]. In the past, materials made of natural fibres such as silk and banana leaf have been employed by several researchers in the past to create composites [3]. Nanocomposites are traditional composites that have only one form of reinforcement. A single matrix material is used to create hybrid composites, which are made up of more than one type of fibre. Hybrid composites are more cost-effective than standard composites because of their special properties. This direction has been taken by a number of researchers. Hybrid polypropylene-banana-glass-fibre composites' mechanical characteristics were calculated by banana fibre reinforced 
polypropylene composites were compared to the hybrid composite findings, and the results showed that 30 weight percent of fibre loading provided the greatest increase in characteristics [4]. Reinforced polyester composites made from banana/glass weave cloth were investigated for their static and dynamic mechanical properties by [5]. Researchers have examined the impact of hybridising glass fibre with banana and sisal fibre with random orientation [6]. They examined the mechanical characteristics of composites made from different-diameter fibres. Hybrid composites perform better than single-fibre composites. Sisal-jute-glass-fibre strengthened epoxy composite was employed to fully understand mechanical qualities like tension, robust strength, and resistance $[7,8]$. According to the results of the research, adding sisal-jute fibre reinforced polymer composites increased the materials' properties. Coir/glass fibre-reinforced epoxy-based hybrid composites were studied for their mechanical properties by [9-11]. The composites' flexural, tensile, and hardness properties, as well as the impacts of fibre loading and fibre length, were all studied. Hybrid composites reinforced with banana and sisal natural fibres are projected to have high tensile and modulus strengths [12]. The results of the experiments are compared to the hybrid mixes rule. The rule of hybrid mixtures found in this study is marginally greater over experimental results due to the formation of microscopic gaps among the fibre and the matrix throughout composite manufacture. This study [13] looked at the composite made of flax, banana fibre, and glass fibre. When it came to impact and flexural stresses, an all-composite material outperformed a single fibre glass reinforced composite (FRP). Composites with hybrid fibres and polymers have received a lot of attention; nevertheless, it is difficult to determine the physical characteristics of polymer composites with unidirectional banana and jute fibres, as demonstrated in the previous review [14]. This research used unidirectional banana and jute fibres to create a blended composites that could easily display hybrid effects on the surface. One composite material's hardness was measured and found to be higher than that of the other two, despite their different densities $[15,16]$.

Kevlar is a high modulus, high tensile strength organic (aramid) fibre. From body armour to aircraft structural elements, it has become a desirable material for many uses. Chemically stable, lightweight, and extremely strong, Kevlar 49 is frequently used due to these advantages [17]. We explore the Kevlar fibre's fundamental physicochemical properties in this research. As a result, we distinguish between research on commercially produced fibre and research on polymers generated in the lab, which could be a completely different material altogether [18]. We explain the fibre's chemical and crystal structure, spectral properties, thermal behaviour, surface properties, and long-term stability. We use mechanical qualities and Kevlar properties, a chemically related but lower modulus fabric, when appropriate.

Because of their high performance-to-weight ratio, fibrereinforced composites hold great promise in a variety of industries $[19,20]$. Particularly in aircraft and other specialised technical fields, carbon fibre composite components are well-known, outperforming normal metallurgical goods in
TABLE 1: Fibre composition in terms of physical, mechanical, and chemical composition.

\begin{tabular}{lcc}
\hline Property & Kevlar & Ramie \\
\hline Density $\left(\mathrm{g} / \mathrm{cm}^{3}\right)$ & 1.44 & 1.50 \\
Diameter $(\mathrm{mm})$ & $85-260$ & 0.034 \\
Tensile strength (MPa) & 2760 & 560 \\
Fracture load (N) & 0.562 & 0.467 \\
Moisture content (wt\%) & 10 & 8.0 \\
Cellulose (wt\%) & 56 & $68.6-76.2$ \\
Lignin (wt\%) & 0.6 & $0.6-0.7$ \\
Hemicellulose (wt\%) & $15.2-16.8$ & $13.1-16.7$ \\
Pectin (wt\%) & 2.0 & 1.9 \\
Wax (wt\%) & 0.32 & 0.3 \\
\hline
\end{tabular}

terms of tensile modulus and weight, while also being lighter. Fibres in the Kevlar aramid family have stronger specific strength, greater extensibility, and a high modulus and could replace carbon fibres in some applications [21]. For these aramid fibres, the starting point is poly-(p-phenylene terephthalamide) (PPT). The rigidity of the molecular chains creates a liquid-crystalline solution. This process will result in a well-organized piece of fabric with pleated sheets that have been assembled in an original fashion. As a result, their use as reinforcing components in engineering assemblies may be limited if they exhibit poor compressional qualities compared to other fibres [22]. For carbon fibre, glass, and Kevlar 49, the ratios of tensile strength to compressive strength are 1.1, 1.9, and 5.0 correspondingly. Kevlar composites' poor performance, according to Greenwood and Rose, is mostly caused by the fibres' extremely low compressive yield strength, not by the matrix [23-25]. Ramie (Boehmeria nivea) is a fibre derived from the ramie plant's stems. In other parts of the world, ramie-based technology and fashion products have not expanded. Removing gum content from the extracted fibres, which can contain up to $30 \%$ gum per weight of fibre, is a significant challenge with ramie. The fibre is not spinnable if the gum is present. Hence, gum must be removed. Ramie, often known as China grass, is an Urticaceae perennial herb. Currently, the majority of it is being planted in China and other Asian nations such as Thailand and the Philippines. Ramie is primarily made up of cellulose (68.6-76.2\%), with little amounts of other gums such hemicellulose (13.1\%-16.7\%), pectin (1.9\%), and wax (0.3\%). When utilised as a textile material, ramie fibre, which is derived from the plant's stem bast, exhibits properties like ultimate tensile, thermal properties, cooling, aeration, wettability, and antimicrobial activities [26].

\section{Materials and Methods}

2.1. Composite Fabrication. Making use of a manual construction method, followed by a moderate compaction process, the composite slabs are made. Table 1 reveals the fibre composition in terms of physical, mechanical, and chemical composition. Fibre loading was used to make 13 different composite sample groupings. Table 2 lists the components and designations of the composites used in this 
Table 2: Denoted by the suffixes $\mathrm{fj}, \mathrm{fb}, m$, and $c$. Composite names and compositions in considerable detail.

\begin{tabular}{|c|c|}
\hline Composites & Composition \\
\hline 1 & Epoxy $(100 \mathrm{wt} \%)$ \\
\hline 2 & Epoxy $(88 w t \%)+$ Nano SiC $(2 w t \%)+$ Kevlar $(10 w t \%)$ \\
\hline 3 & Epoxy $(78 w t \%)+$ Nano SiC $(2 w t \%)+$ Kevlar $(20 w t \%)$ \\
\hline 4 & Epoxy $(68 w t \%)+$ Nano SiC $(2 w t \%)+$ Kevlar $(30 w t \%)$ \\
\hline 5 & Epoxy $(58 w t \%)+$ Nano SiC $(2 w t \%)+$ Kevlar $(40 w t \%)$ \\
\hline 6 & Epoxy $(88 w t \%)+$ Nano $\operatorname{SiC}(2 w t \%)+\operatorname{ramie}(10 w t \%)$ \\
\hline 7 & Epoxy $(78 w t \%)+$ Nano SiC $(2 w t \%)+$ ramie $(20 w t \%)$ \\
\hline 8 & Epoxy $(68 w t \%)+$ Nano SiC $(2 w t \%)+$ ramie $(30 w t \%)$ \\
\hline 9 & Epoxy $(58 w t \%)+$ Nano SiC $(2 w t \%)+$ ramie $(40 w t \%)$ \\
\hline 10 & Epoxy $(88 w t \%)+$ Nano SiC $(2 w t \%)+\operatorname{Kevlar}(5 w t \%)+\operatorname{ramie}(5 w t \%)$ \\
\hline 11 & Epoxy $(78 w t \%)+$ Nano SiC $(2 w t \%)+$ Kevlar $(10 w t \%)+$ ramie $(10 w t \%)$ \\
\hline 12 & Epoxy $(68 w t \%)+$ Nano SiC $(2 w t \%)+$ Kevlar $(15 w t \%)+$ ramie $(15 w t \%)$ \\
\hline 13 & $\operatorname{Epoxy}(58 w t \%)+\operatorname{Nano} \mathrm{SiC}(2 w t \%)+\operatorname{Kevlar}(20 w t \%)+$ ramie $(20 w t \%)$ \\
\hline
\end{tabular}

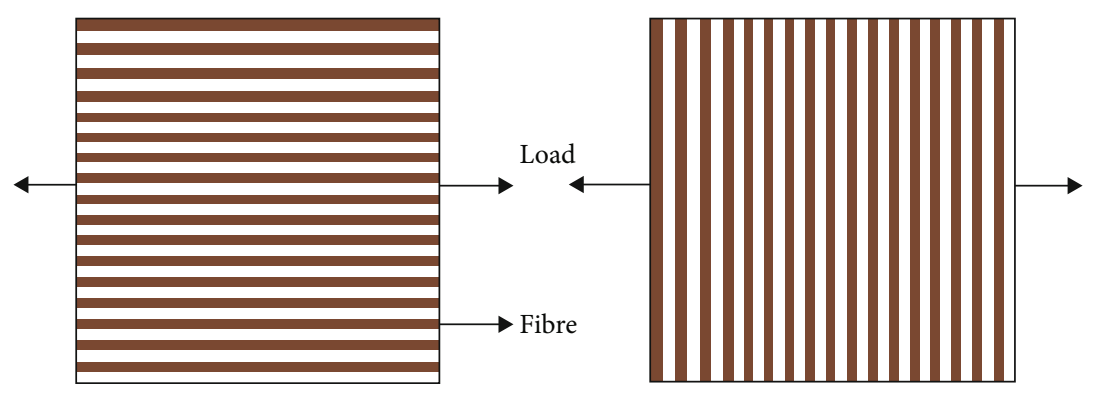

FIGURE 1: Fibre arrangement in two directions: (a) longitudinally and (b) transversally.

research. Epoxy resins and curing agents typically contain more than one reaction site per molecule. The curing process to form three-dimensional network results from multiple reactions between epoxide molecules and the curing agent. The epoxy and hardener HY951 are combined according to the package directions in a $10: 1$ weight ratio. The matrix material was reimpregnated into Kevlar, Ramie fibres, and nano SiC. On the two ends of the wooden moulds, mould release papers and mould release spray are employed, respectively, to swiftly and simply remove the composite material. Air bubbles were carefully avoided by being extra careful during the preparation process. After applying pressure from the top, the mould was curing at ambient temperature for 48 hours. After 48 hours, a diamond cutter was used to cut this sample into the required size for testing the materials' physical and mechanical properties both longitudinally and transversely. Figure 1 depicts this in both longitudinal and transverse directions. Table 3 reveals the composite densities, both theoretically and experimentally.

2.2. Density. Agarwal and Broutman's Equation (1) calculates the density of composites as a purely theoretical concept as weight fractions of various constituents combined.

$$
\rho_{\mathrm{ct}}=\frac{1}{\left(W_{\mathrm{fj}} / \rho_{\mathrm{fj}}\right)+\left(W_{\mathrm{fb}} / \rho_{\mathrm{fb}}\right)+\left(W_{m} / \rho_{m}\right)},
$$

where $W$ and $\rho$ denote weight and density are shown.

The Archimedes principle or water immersion approach can be used to ascertain the composite's true density empirically (ASTM D 792-91). In accordance with the ASTM D2734-70 standard process, the composite material's void content was determined. Equation (2) was used to compute the composite's void volume fraction, $V_{v}$, ct, and ce represent densities in theory and in experiments, respectively, for the composite.

$$
V_{v}=\frac{\rho_{\mathrm{ct}}-\rho_{\mathrm{ce}}}{\rho_{\mathrm{ct}}}
$$

2.3. Tensile Strength. While doing a tension test, flat specimens are commonly employed. To date, the dog-bone specimen and direct experiment with terminal tab have proven to be the most popular specimen geometries. In this inquiry, a straight-sided specimen is used for the tensile test. Fibrereinforced composites' tensile properties, the ASTM standard test is D3039-14. These are the specimen's longitudinal 
TABle 3: Composite densities, both theoretically and experimentally.

\begin{tabular}{lccc}
\hline Composition & Theoretical density $(\mathrm{gm} / \mathrm{cc})$ & Experimental density $(\mathrm{gm} / \mathrm{cc})$ & Volume fraction of voids $(\%)$ \\
\hline C1 & 1.210 & 1.581 & 0.36 \\
C2 & 1.268 & 1.592 & 10.42 \\
C3 & 1.381 & 1.612 & 2.562 \\
C4 & 1.389 & 1.581 & 3.789 \\
C5 & 1.412 & 1.568 & 5.121 \\
C6 & 1.361 & 1.516 & 1.243 \\
C7 & 1.372 & 1.556 & 2.281 \\
C8 & 1.385 & 1.584 & 3.382 \\
C9 & 1.412 & 1.593 & 4.137 \\
C10 & 1.368 & 1.542 & 1.306 \\
C11 & 1.372 & 1.551 & 2.601 \\
C12 & 1.412 & 1.583 & 2.891 \\
C13 & 1.462 & 1.596 & 4.012 \\
\hline
\end{tabular}

and transverse measurements in millimeters and millimeters, respectively. The ductility of the composite samples was calculated with standard diagnostic tools and a head speed of 2 millimeters per second when spinning in a circle. The mean value of three similar composites was recorded as a composite property, and the results were compared.

2.4. Flexural Strength. Composites have a flexural strength, which is defined as the amount of tensile stress they can bear before they break when bent. When pressure builds up to the center of the frame, the sample bends and cracks. For the flexural test, Instron 1195 universality equipment and ASTM D790 [21] procedure were used on rectangular composite sample specimens. Dimensions are $100 \mathrm{~mm}$ in length, $12.7 \mathrm{~mm}$ in width, and $4 \mathrm{~mm}$ in thickness if the specimen is oriented transversely. We used a $10 \mathrm{kN}$ load cell and loaded the cylinder at 2 millimeters per minute. Using Eq. (3), we can calculate the composite specimen's flexural strength.

$$
\frac{3 \mathrm{PL}}{2 \mathrm{bt}^{2}}
$$

where $b$ is the samples breadth, and $t$ is the sample thickness; $t$ is the sample's length span; and where $P$ denotes the failure load in Newtons. Three identical examples of each form of composite were evaluated, as well as the median value was recorded as a composite attribute.

2.5. Interlaminar Shear Strength. To get the strength of the interlaminar band value, the composite samples are subjected to brief beam shear tests at room temperature. ASTM standard D2344-84 is used for the test, and the same universal testing machine is used. The sample's $45 \mathrm{~mm} \times 10 \mathrm{~mm}$ $\times 4 \mathrm{~mm}$ are the measurements, and the crosshead moves at a speed of $2 \mathrm{~mm}$ per minute. A downward force from the loading cylinder causes normal (bending) and transverse shear stresses on the specimen. Interlaminar shear failure occurs when a fracture develops along the horizontal plane between two laminates because of the beam's shortness. The composite specimen's interlaminar shear strength can be calculated using Eq. (4). Three identical examples of each composite type were evaluated, additionally, the composite's mean value was revealed as an attribute.

$$
\frac{3 P}{4 b t}
$$

2.6. Properties of Impact and Microhardness. The composite samples are put through instrumented low-speed impact testing. The pendulum impact testing equipment measures the energy expended while using a pendulum hammer to break the V-notched specimen. The specimen's crosssection is used to link this energy with its magnitude. ASTM D 256 provides specimen dimensions of $64 \mathrm{~mm} 12.7 \mathrm{~mm}$ $4 \mathrm{~mm}$ and a notching depth of $10 \mathrm{~mm}$. Specimens must fulfil these specifications. On a dial indicator, the impact energy values of several specimens were recorded. To press the diamond indenter into the material, apply tension to the material's surfaces. Indentation in the material's two diagonals $X$ and $Y$ has an arithmetic mean $L$. After a load is removed is calculated. Equation (5) is utilised in the current investigation to calculate the load assumed to be $F=24.54 \mathrm{~N}$ and the Vickers hardness value.

$$
\begin{aligned}
& H_{\mathrm{v}}=0.1889 \frac{F}{L^{2}}, \\
& \text { And } L=\frac{X+Y}{2} .
\end{aligned}
$$

When you apply a force, you get a square impression diagonal in millimeters, which is equal to the applied force multiplied by the length in millimeters of the horizontal line and the vertical line, respectively. The mean value of three similar composites was recorded as a composite property, and the results were compared.

\section{Results and Conclusions}

3.1. Fibre Loading Effects on Composite Density. One of the most essential aspects of composites is their density, which is 


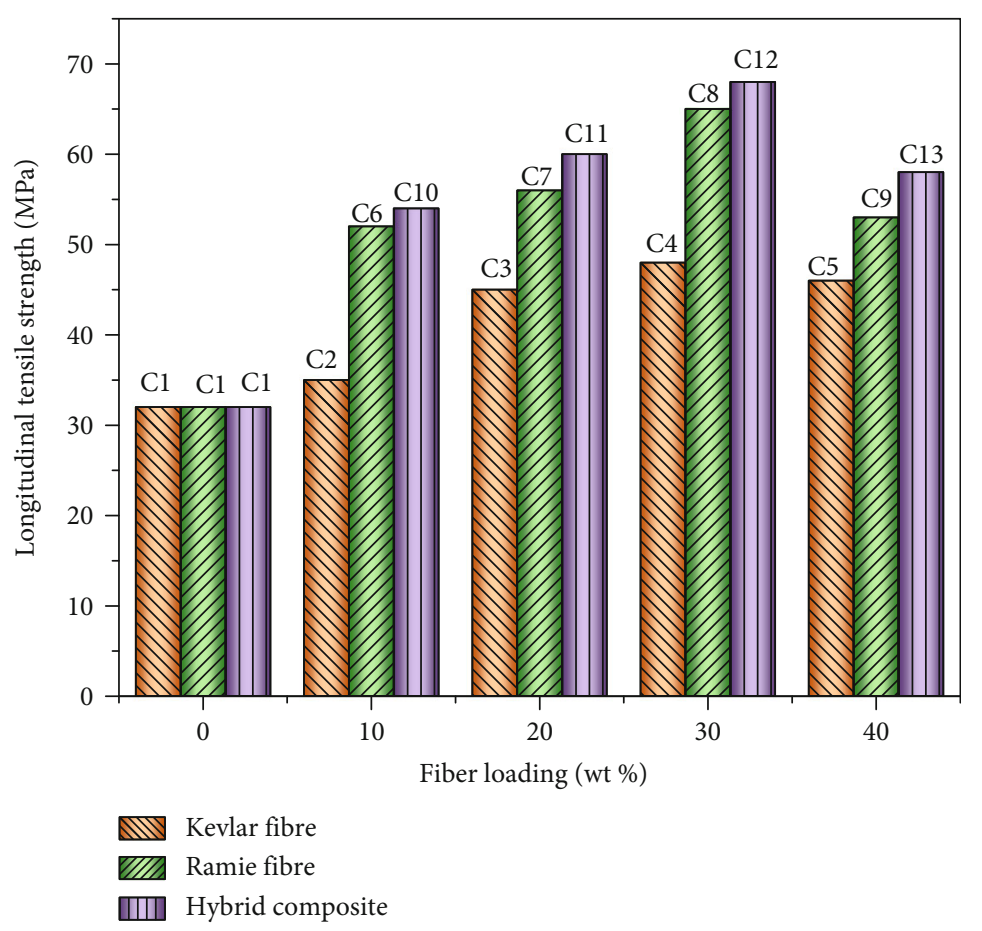

Figure 2: Fibre loading and composites' longitudinal tensile strength.

determined by the ratio of matrix to reinforcing components. The inclusion of voids in the composite is the primary cause of the discrepancy between predicted and experimental densities. As a result, knowing the sample's void \% is crucial. Densities of Kevlar, Ramie, and Kevlar/Ramie composites, as well as the corresponding void volume percentages, are studied theoretically and experimentally. It was discovered that the Kevlar composite had more voids than expected due to insufficient Epoxy matrix wetting of Kevlar fibres. As the Ramie fibre loading in the Kevlar composite was increased, the hybrid composites' void content decreased. Lumens in the cellular structure of natural fibres act as voids. This means that the fibre naturally contains these voids. As a result, an increase in fibre loading may be causing an increase in void content. Whether or not a composite contains voids has a substantial impact on its mechanical qualities.

3.2. Tensile Properties Impact by Fibre Loading. Figure 2 shows the outcome of fibre loading on composite lengthto-width ratio. At 30 weight percent fibre loading, the maximum tensile strength for the entire length of Kevlar composites, Ramie composites, and Kevlar/Ramie composites ranges from $50.8 \mathrm{MPa}$ to $66.87 \mathrm{MPa}$. The matrix can transmit stress to the fibres because of the reinforcing provided by the fibres. Because there are fewer fibres in the matrix with a lower fibre loading, the matrix experiences localised strains even at low loads. The tensile characteristics of composites with a fibre loading of $40 \%$ or more are reduced. Fibre packing and insufficiently rich epoxy areas are likely causes of divergence at increased fibre loading. In addition, the composite has the potential for fibre entanglements and agglomeration, which reduces the matrix and fibre stress transfer, and this is beneficial.
Similar results have been reported for fibre epoxy composite by [25]. Fibre loading has an impact on composite transverse tensile strength, as seen in Figure 3. This composite's transverse tensile strength was calculated at 41.58 MPa when loaded with 20 weight percent of Kevlar fibres. The torsional, flexion, and interlaminar shear modulus of a matrix-dominated material is decreased by porosity and vacancies.

3.3. Flexural Properties Impact by Fibre Loading. Figures 4 and 5 depict the composites' response to fibre loading both the longitudinal and transverse flexural strengths. The fibre loading has a substantial impact on flexural characteristics, as can be seen. The composite's longitudinal flexural strength is boosted by 30 weight percent of fibre loading and then decreased by an increasing amount of fibre loading. Composites made from a mix of materials have better flexural strength than unhybridized composites for each fibre loading. Composites made from a mix of materials have more compatibility and dispersion than traditional composites, allowing for better stress transferability. Ramie composite and Kevlar/Ramie composite have increased longitudinal flexural strength by 72, 104, and 128 percent, respectively. A hybrid composite's transverse flexural strength increases by up to $10 \%$. In weight before falling when the amount of fibre loading is increased. It is because to weak interfacial bonding, fibre tangling at increased stress, and the epoxy's inefficient wetting of the fibres that the composites lose their flexural strength.

3.4. Interlaminar Shear Strength and Fibre Loading Interactions. An interlaminar composite has stresses at the boundary between two adjacent layers. Due to these strains, 


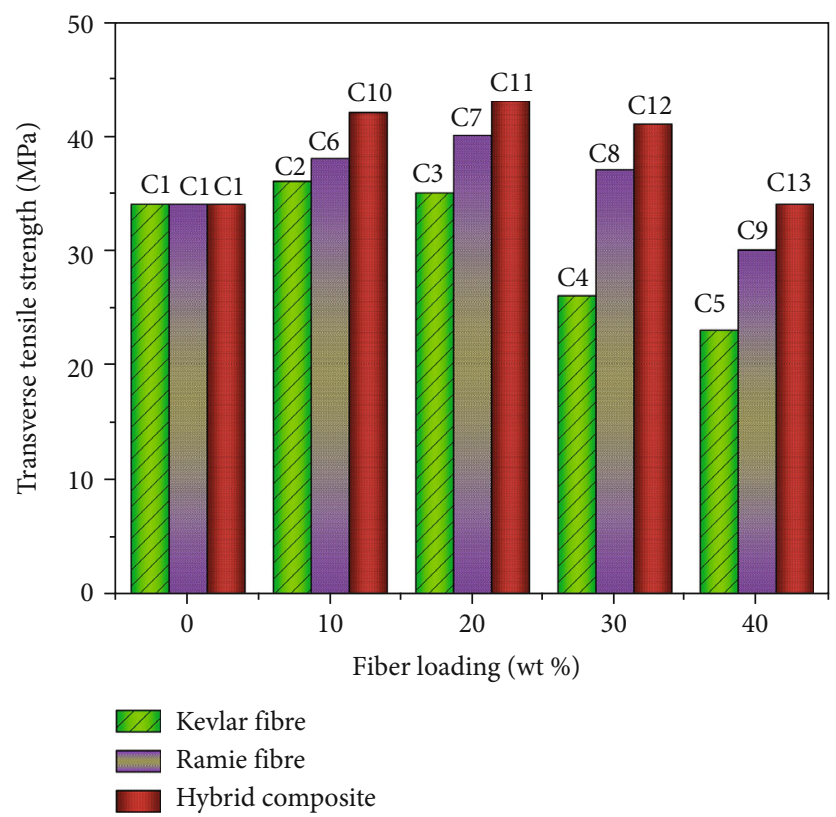

FIGURE 3: The influence of fibre loading on composites' transverse tensile strength.

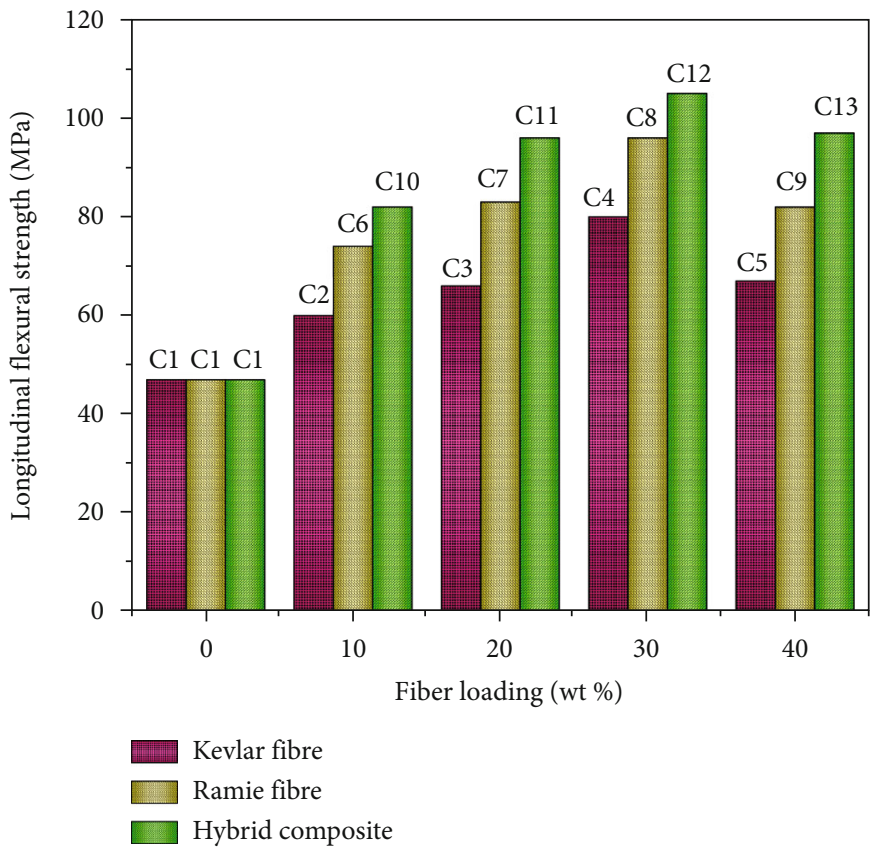

FIgURE 4: Fibre loading effects composites' longitudinal flexural strength.

the adjacent layers deform relative to one another, and if the stresses are high enough, failure may occur in the midplane between the layers. Fibre loading affects composite interlaminar shear strength, as seen in Figure 6. Adding fibre up to 30 weight percent of fibre loading increases interlaminar shear strength, while adding another 40 weight percent causes interlaminar shear strength to decrease. Single and hybrid fibre reinforced composites both display this trend. This decrease may be attributable to the creation of voids in the matrix, which commonly occurs in the interlaminar area of composites. Shear strength between the laminae in a single layer Kevlar/Ramie composite with 30 weight percent of fibre loading reached $102.82 \mathrm{MPa}$ in the current study.

3.5. Impact and Microhardness Properties Affected by Fibre Loading. Impact tests are performed to determine a material's tensile strength. During plastic deformation, the toughness of a material is determined by its ability to absorb energy. Fibre loading has a noticeable effect on a composite's impact energy, which can be shown in Figure 7. The graph 


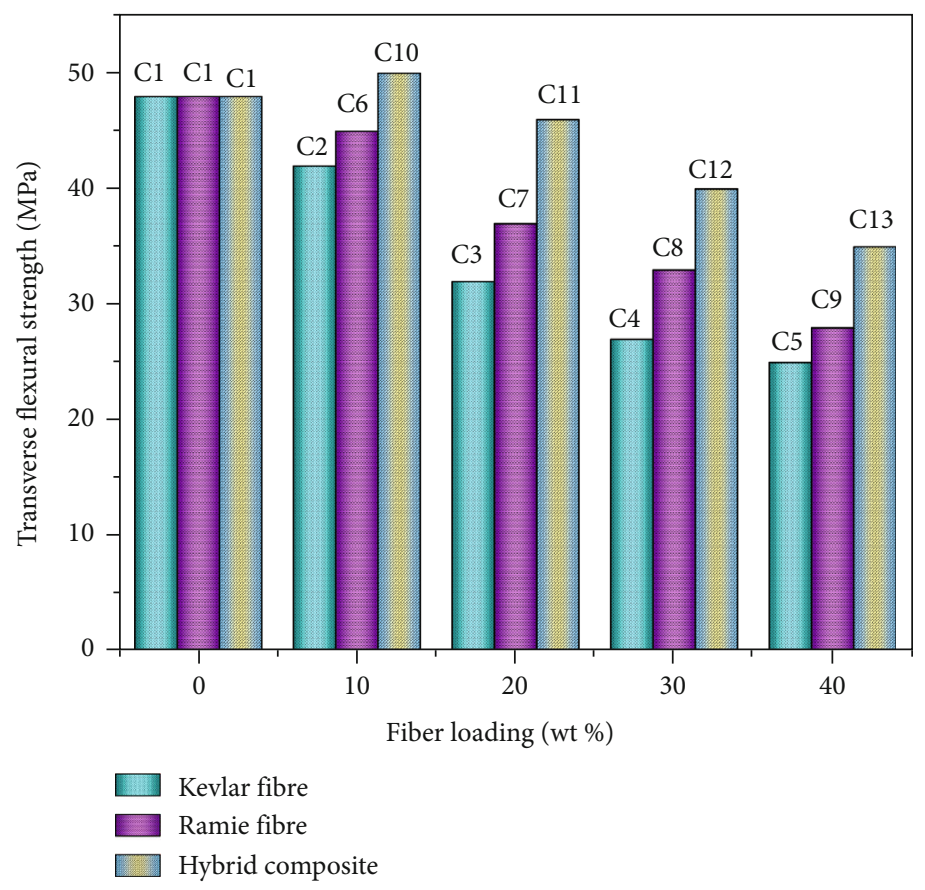

FIGURE 5: The influence of fibre loading on composites' transverse flexural strength.

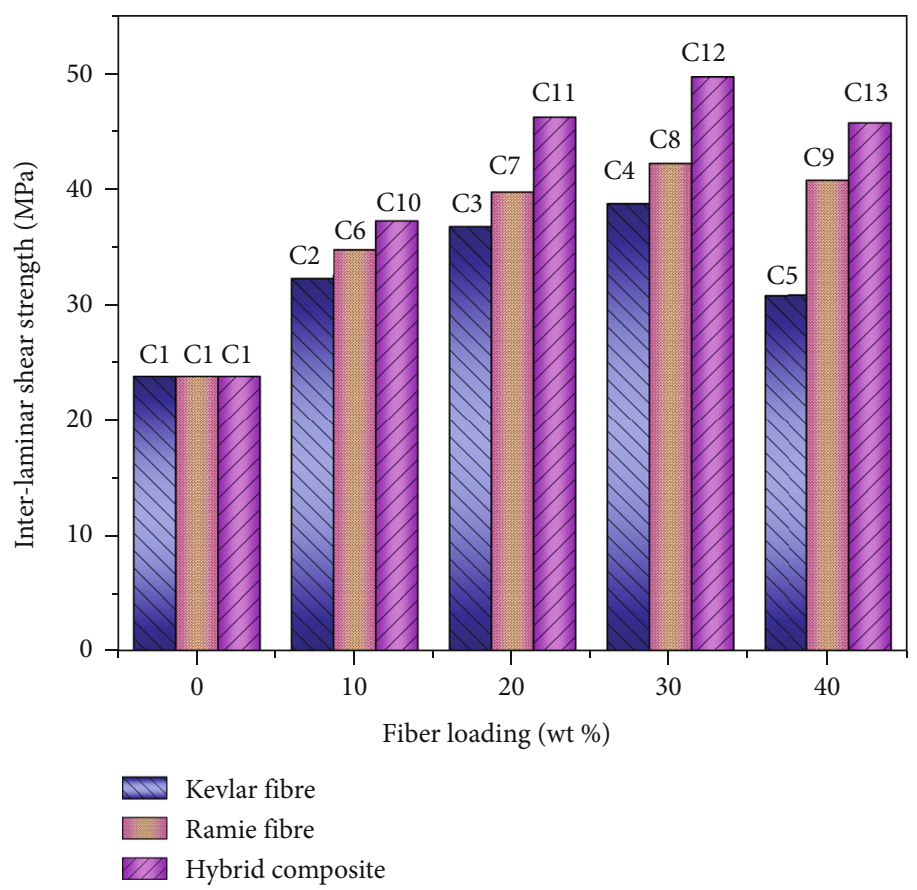

FIGURE 6: Composites' interlaminar shear strength is affected by fibre loading.

illustrates that when the amount of fibre is increased, so does the impact energy of the composite. Individual natural fibre composites have a lower impact energy than hybrid composites, the research shows. Fibre breakage, matrix fracture, and pull out are all causes of specimen failure. Crack propagation occurs when the fibres lose their adherence to the matrix and the matrix separates from the fibres. According to the research, adding Ramie fibre to Kevlar improved the bond- ing capacity, expanded the area under the frustration curve, and increased the impact strength. Figure 8 reveals the impact testing arrangement.

At $40 \%$ fibre loading, the Kevlar/Ramie hybrid composite had a maximum impact energy of $4.085 \mathrm{~J}$. As the fibre loading increases, a small number of researchers have also identified an increased trend in the impact strength value. More fibre loading means stronger impact since it 


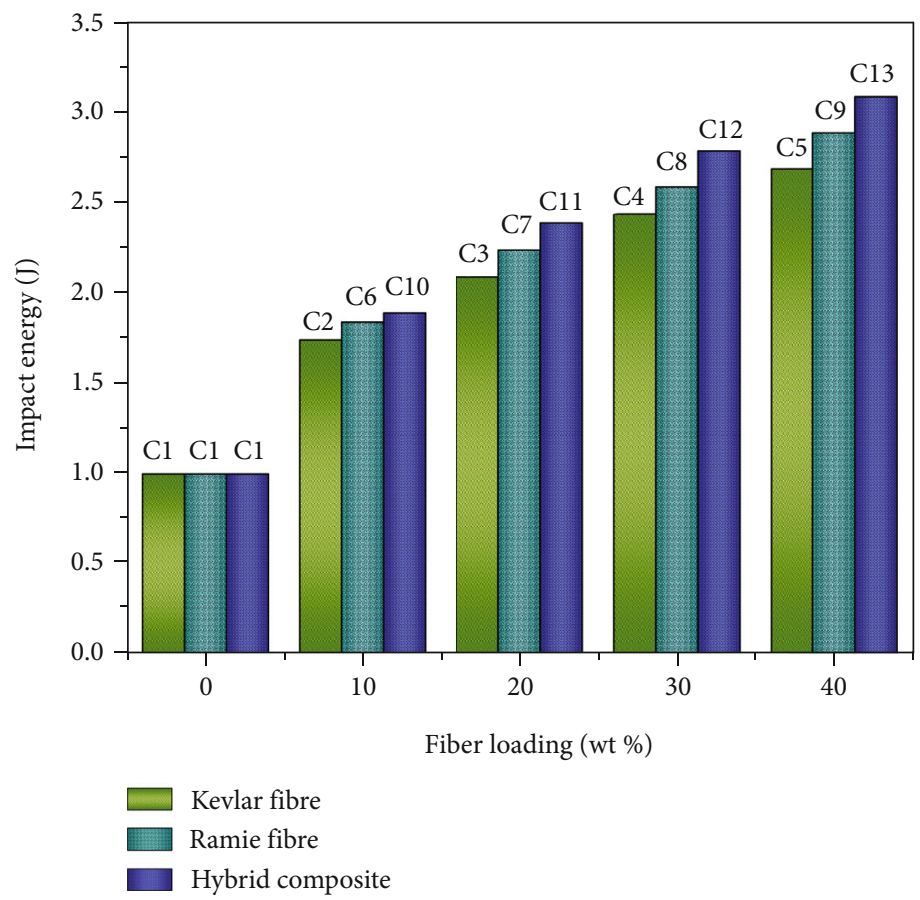

FIgURE 7: Composites' impact energy and fibre loading.

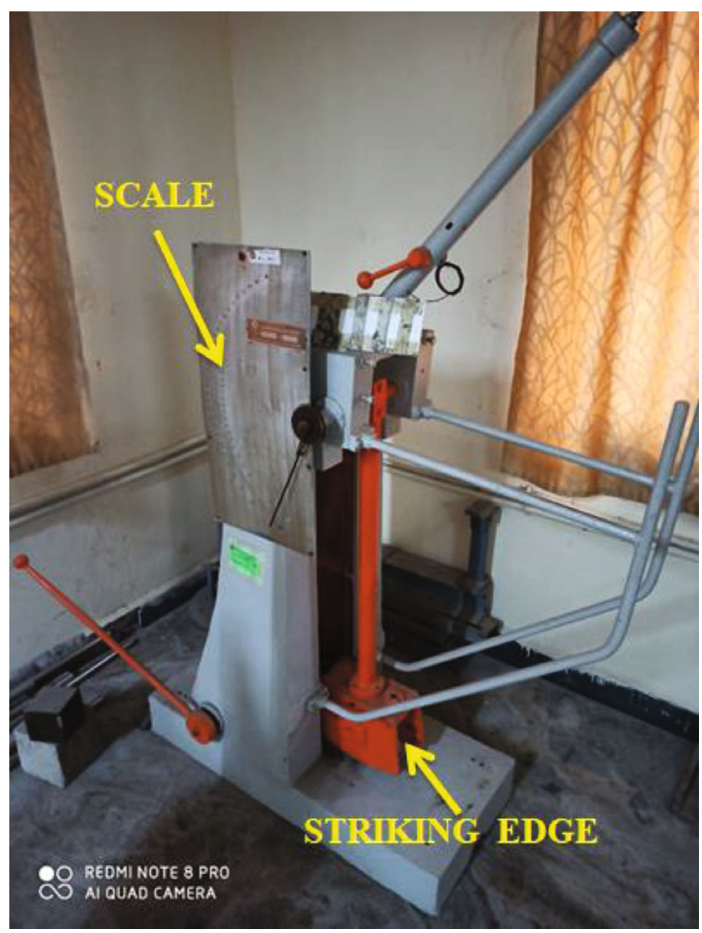

FIGURE 8: Impact testing arrangement.

takes more a sufficient amount of energy to separate the tangled web of fibres. Fibre loading has an impact on composite microhardness, as seen in Figure 9. When compared to Kevlar composite and Ramie composite, the Kevlar/Ramie composite had the highest microhardness. Increases in fibre loading result in an increase in composite hardness. Fibre improves the composite's modulus, which in turn increases the fibre's hardness. Since hardness is dependent on fibre volume and modulus, this makes sense. The lignocellulosic fibre's brittleness may be to blame for the increase in microhardness. Hybrid fibre reinforced composites have a microhardness rating that is 65 percent higher when 40 weight percent fibre loading is used. 


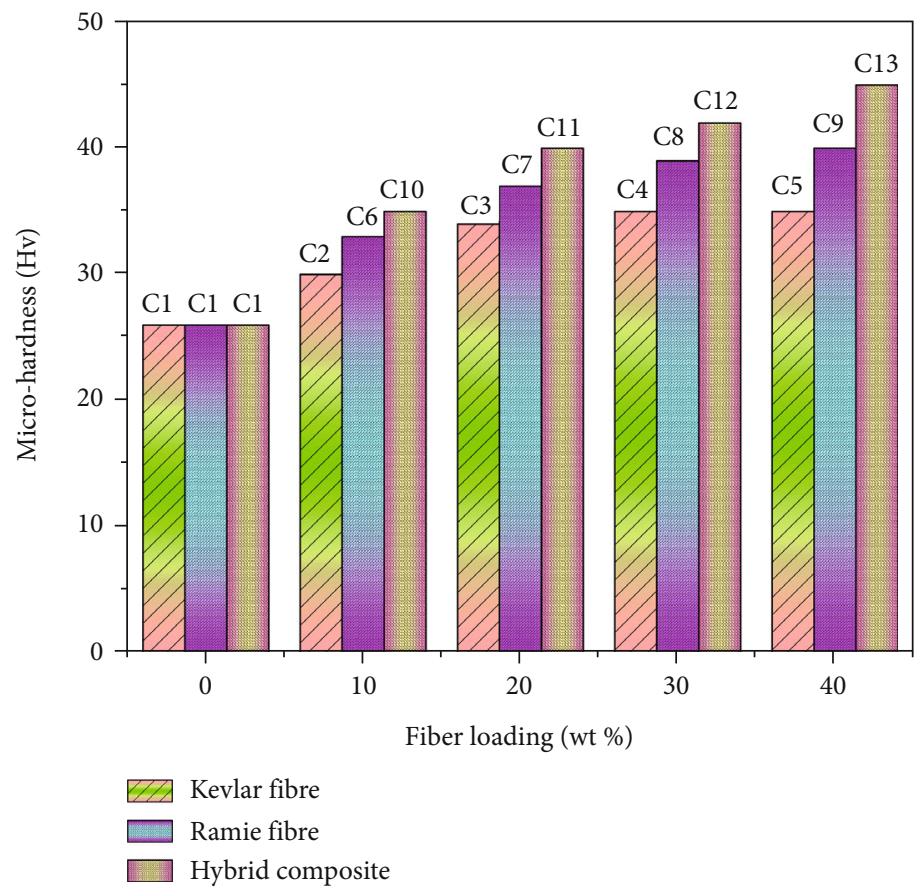

FIGURE 9: Fibre loading and composite microhardness.

Photograph of a broken Kevlar/Ramie fibre reinforced epoxy based hybrid composite specimen taken in longitudinal direction during tensile testing. When the fibre loading is 30 percent of excellent interfacial adhesion between the fibre and matrix, and matrix weight results in outstanding hybrid composite strength properties. Lack of bond strength among the fibre and the matrix at a $40 \%$ fibre loading resulted in fibre breakage, fibre draw out, and porosity or air impalements. An example of a broken Kevlar/Ramie hybrid composite tensile test specimen cracked only in one direction. Fracture and crack growth and fibre rip out are all evident on the surface with a $40 \%$ fibre loading, all of which contribute to poor hybrid composite mechanical qualities.

\section{Conclusions}

Kevlar/Ramie hybrid composites with fibre-reinforced epoxy resins were experimentally investigated for physical and mechanical characteristics, and the following findings were made as a result:

(i) Fibre-reinforced epoxy resins can be used to successfully fabricate unidirectional Kevlar, Ramie, and Kevlar/Ramie fibre hybrid composites using a simple hand lay-up approach

(ii) The amount of fibre in the composite material can significantly impact the material's various properties. The void content of hybrid and single-fibre composite materials rises directly to the increase in fibre loading

(iii) The composite's longitudinal tensile and flexural strength improve with a $30 \mathrm{wt} \%$ fibre loading, but these properties degrade with a higher percentage. In millimeters per inch, tensile strength was measured (Mpa). In millimeters per inch, flexural strength was measured (MPa). The composite material's transverse tensile and flexural strength increase as the fibre loading increases

(iv) The interlaminar shear strength of the Kevlar/ Ramie composite with $30 \mathrm{wt} \%$ fibre loading is $102.82 \mathrm{MPa}$. The impact strength of the hybrid composite is higher than that of a single component. Microhardness increased brittleness at the atomic level by 65 percent when 40 percent of the fibre loading is incorporated into the hybrid fibre reinforced composite compared to plain epoxy

\section{Data Availability}

The data used to support the findings of this study are included in the article. Should further data or information be required, these are available from the corresponding author upon request.

\section{Conflicts of Interest}

The authors declare that there are no conflicts of interest regarding the publication of this paper.

\section{References}

[1] R. Gujjala, S. Ojha, S. K. Acharya, and S. K. Pal, "Mechanical properties of woven jute-glass hybrid-reinforced epoxy composite," Journal of Composite Materials, vol. 48, no. 28, pp. 3445-3455, 2014. 
[2] V. Mohanavel, S. Suresh Kumar, J. Vairamuthu, P. Ganeshan, and B. NagarajaGanesh, "Influence of stacking sequence and fiber content on the mechanical properties of natural and synthetic fibers reinforced penta-layered hybrid composites," Journal of Natural Fibers, vol. 2021, article 1875368, pp. 113, 2021.

[3] J. Rout, M. Misra, A. K. Mohanty, S. K. Nayak, and S. S. Tripathy, "SEM observations of the fractured surfaces of coir composites," Journal of Reinforced Plastics and Composites, vol. 22, no. 12, pp. 1083-1100, 2003.

[4] V. Mishra and S. Biswas, "Physical and mechanical properties of bi-directional jute fiber epoxy composites," Procedia engineering, vol. 51, pp. 561-566, 2013.

[5] S. L. Bai, R. K. Y. Li, L. C. M. Wu, H. M. Zeng, and Y. W. Mai, "Tensile failure mechanisms of sisal fibers in composites," Journal of Materials Science Letters, vol. 17, no. 21, pp. 18051807, 1998.

[6] S. M. Sapuan, A. Leenie, M. Harimi, and Y. K. Beng, "Mechanical properties of woven banana fibre reinforced epoxy composites," Materials and Design, vol. 27, no. 8, pp. 689-693, 2006.

[7] S. Banerjee and B. V. Sankar, "Mechanical properties of hybrid composites using finite element method based micromechanics," Composites. Part B, Engineering, vol. 58, pp. 318-327, 2014.

[8] S. K. Samal, S. Mohanty, and S. K. Nayak, "Banana/glass fiberreinforced polypropylene hybrid composites: fabrication and performance evaluation," Polymer - Plastics Technology and Engineering, vol. 48, no. 4, pp. 397-414, 2009.

[9] L. A. Pothan, P. Potschke, R. Habler, and S. Thomas, “The static and dynamic mechanical properties of banana and glass fiber woven fabric-reinforced polyester composite," Journal of Composite Materials, vol. 39, no. 11, pp. 1007-1025, 2005.

[10] V. P. Arthanarieswaran, A. Kumaravel, and M. Kathirselvam, "Evaluation of mechanical properties of banana and sisal fiber reinforced epoxy composites: influence of glass fiber hybridization," Materials and Design, vol. 64, pp. 194-202, 2014.

[11] F. Liu, D. Wang, J. Liu et al., "Reviews on interfacial properties of the carbon fiber reinforced polymer composites," Journal of Physics: Conference Series, vol. 1637, no. 1, p. 12027, 2020.

[12] M. Ramesh, K. Palanikumar, and K. H. Reddy, "Plant fibre based bio-composites: sustainable and renewable green materials," Renewable and Sustainable Energy Reviews, vol. 79, pp. 558-584, 2017.

[13] M. Idicula, N. R. Neelakantan, Z. Oommen, K. Joseph, and S. Thomas, "A study of the mechanical properties of randomly oriented short banana and sisal hybrid fiber reinforced polyester composites," Journal of Applied Polymer Science, vol. 96, no. 5, pp. 1699-1709, 2005.

[14] T. P. Sathishkumar, P. Navaneethakrishnan, S. Shankar, and J. Kumar, "Mechanical properties of randomly oriented snake grass fiber with banana and coir fiber-reinforced hybrid composites," Journal of Composite Materials, vol. 47, no. 18, pp. 2181-2191, 2013.

[15] M. Jawaid, H. P. S. A. Khalil, A. A. Bakar, A. Hassan, and R. Dungani, "Effect of jute fibre loading on the mechanical and thermal properties of oil palm-epoxy composites," Journal of Composite Materials, vol. 47, no. 13, pp. 1633-1641, 2013.

[16] V. K. Bhagat, S. Biswas, and J. Dehury, "Physical, mechanical, and water absorption behavior of coir/glass fiber reinforced epoxy based hybrid composites," Polymer Composites, vol. 35, no. 5, pp. 925-930, 2014.

[17] V. S. Srinivasan, S. Rajendra Boopathy, D. Sangeetha, and B. Vijaya Ramnath, "Evaluation of mechanical and thermal properties of banana-flax based natural fibre composite," Materials and Design, vol. 60, pp. 620-627, 2014.

[18] B. D. Agarwal, L. J. Broutman, and C. W. Bert, Analysis and Performance of Fiber Composites, John Wiley \& Sons, 1981.

[19] A. Standard, D6641/D6641M-14, Standard Test Method for Compressive Properties of Polymer Matrix Composite Materials Using a Combined Loading Compression (CLC) Test Fixture, ASTM International, West Conshohocken, PA, 2014.

[20] I ASTM, Standard test methods for flexural properties of unreinforced and reinforced plastics and electrical insulating materials, ASTM D790-07, 2007.

[21] J. P. Dhal and S. C. Mishra, "Processing and properties of natural fiber-reinforced polymer composite," Journal of Materials, vol. 2013, Article ID 297213, 6 pages, 2013.

[22] A. Elbehiry, O. Elnawawy, M. Kassem, A. Zaher, and M. Mostafa, "FEM evaluation of reinforced concrete beams by hybrid and banana fiber bars (BFB)," Case Studies in Construction Materials, vol. 14, article e00479, 2021.

[23] H. Cabral, M. Cisneros, J. M. Kenny, A. Vazquez, and C. R. Bernal, "Structure-properties relationship of short jute fiberreinforced polypropylene composites," Journal of Composite Materials, vol. 39, no. 1, pp. 51-65, 2005.

[24] S. Mahna, H. Singh, S. Tomar, D. Bhagat, A. Patnaik, and S. R. Kumar, "Dynamic mechanical behavior of nano- $\mathrm{ZnO}$ reinforced dental composite," Nanotechnology Reviews, vol. 8, no. 1, pp. 90-99, 2019.

[25] C. V. Srinivasa and K. N. Bharath, "Impact and hardness properties of areca fiber-epoxy reinforced composites," Journal of Materials and Environmental Science, vol. 2, no. 4, pp. 351356, 2011.

[26] M. Idicula, K. Joseph, and S. Thomas, "Mechanical performance of short banana/sisal hybrid fiber reinforced polyester composites," Journal of Reinforced Plastics and Composites, vol. 29, no. 1, pp. 12-29, 2010. 